
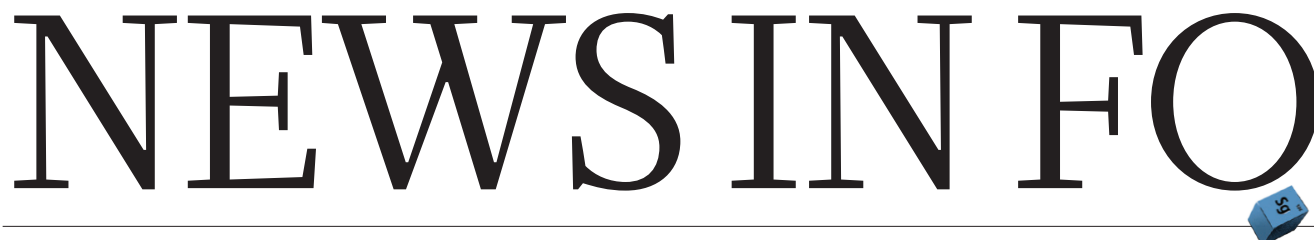

JAPAN Approval of stem-cell therapy for spinal-cord injury raises concerns $\mathbf{p . 5 4 4}$
Kosovo Proposed land swaps threaten multi-ethnic research collaborations p. 546
ECOLOGY Lush Ethiopian church forests are biodiversity refuge $\mathbf{p . 5 4 8}$

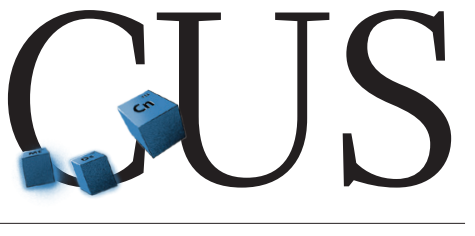

CHEMISTRY Experiments explore the edge of the periodic table $\mathbf{p . 5 5 2}$

\title{
Drones unleashed against invasive Galapagos rats
}

Tiny helicopters deliver poisoned bait to islands where rodents threaten native species.

\section{BY EMMA MARRIS}

A conservation group is using drones to eradicate invasive rats by dropping poison on two small islands in Ecuador's Galapagos archipelago - the first time such an approach has been used on vertebrates in the wild. The operation, which began on 12 January on North Seymour island in the Galapagos National Park, aims to protect native animals and plants from the destructive rodents.

Rats and other non-native species have caused extensive damage to the Galapagos, whose unique flora and fauna evolved in isolation for millions of years. In the process, native species lost many defence mechanisms against predators. Rats, which reproduce quickly and eat a wide variety of plants and animals, have been a target of eradication campaigns across the Galapagos.

North Seymour had been rat-free since 2007, but last year, two species of rat were detected there, says Karl Campbell, a pest-control specialist at Island Conservation, the conservation group in Santa Cruz, California, that is coordinating the drone operation with the managers of Ecuador's Galapagos National Park.

The rats eat the eggs and nestlings of the island's seabirds, including storm petrels and Galapagos shearwaters. The rodents also threaten the fragrant palo santo tree (Bursera graveolens) and Opuntia cactuses by gnawing on their limbs and eating their seeds. Conservationists hope that if rats are eradicated from North Seymour, vulnerable lava gulls (Larus fuliginosus) that have disappeared from the 
- island will return to nest once again.

Drones were chosen for the job because they are cheaper than a tried and tested tool helicopters - but safer and easier than spreading the bait by hand on the extremely rugged terrain of the 184-hectare island.

On 12 January, a team using two six-rotor drones started spreading bait laced with rat poison around North Seymour island and the nearby islet of Mosquera. Each drone can carry up to 20 kilograms of bait for up to 15 minutes.

Mechanical difficulties with the drones shut the operation down when only half of North Seymour was treated, and workers had to spread the rest of the bait by hand - creating a natural experiment that could provide useful data on the drone approach. Island Conservation plans to compare outcomes in the drone-baited and hand-baited halves of the island.

The group intends to drop a second round of bait by drone in a few weeks. It will then monitor rat activity on the island for two years.

The project might be the first of its kind, but Campbell and others in the field expect drones to play an increasing part in culling non-native animals that threaten rare species. Especially on small, remote islands, far from helicopter companies, drones could be a much cheaper way to spread poison. Poisoning rats requires dropping bait twice, 21 days apart, Campbell says. "You have to have a helicopter for a month, sometimes shipped by boat. Your expenses very quickly add up."

Using drones for animal control is new, but conservation scientists are increasingly using the devices to monitor animals and ecosystems, and even to collect samples or spread seeds, says Serge Wich, a biologist at Liverpool John Moores University, UK, and a co-director of the Conservation Drones website, which follows the tool's rise in the field. "Almost every conservation organization I work with is using drones now, in one way or another," he says.

Craig Morley, an invasive-species specialist at the Toi Ohomai Institute of Technology in Rotorua, New Zealand, will be watching the Galapagos project closely. He is researching the use of modified drones to lay poison for Australian brush-tailed possums (Trichosurus vulpecula), which are considered pests in New Zealand because they eat the leaves and flowers of rare plants and snack on the chicks and eggs of native birds. New Zealand has set a goal of eliminating possums, rats and other predators from the country by 2050 .

One advantage of using drones, Morley says, is that it reduces the need to cut trails through a forest to lay poison baits or traps.

But using drones to kill could also change how conservation scientists view such work, Morley says, comparing the approach to modern warfare. "You used to be able to see your opponent. Now, you just a press a button and you fire a missile," he says. "You become a little bit detached from the reality that you have killed something or somebody over there." -

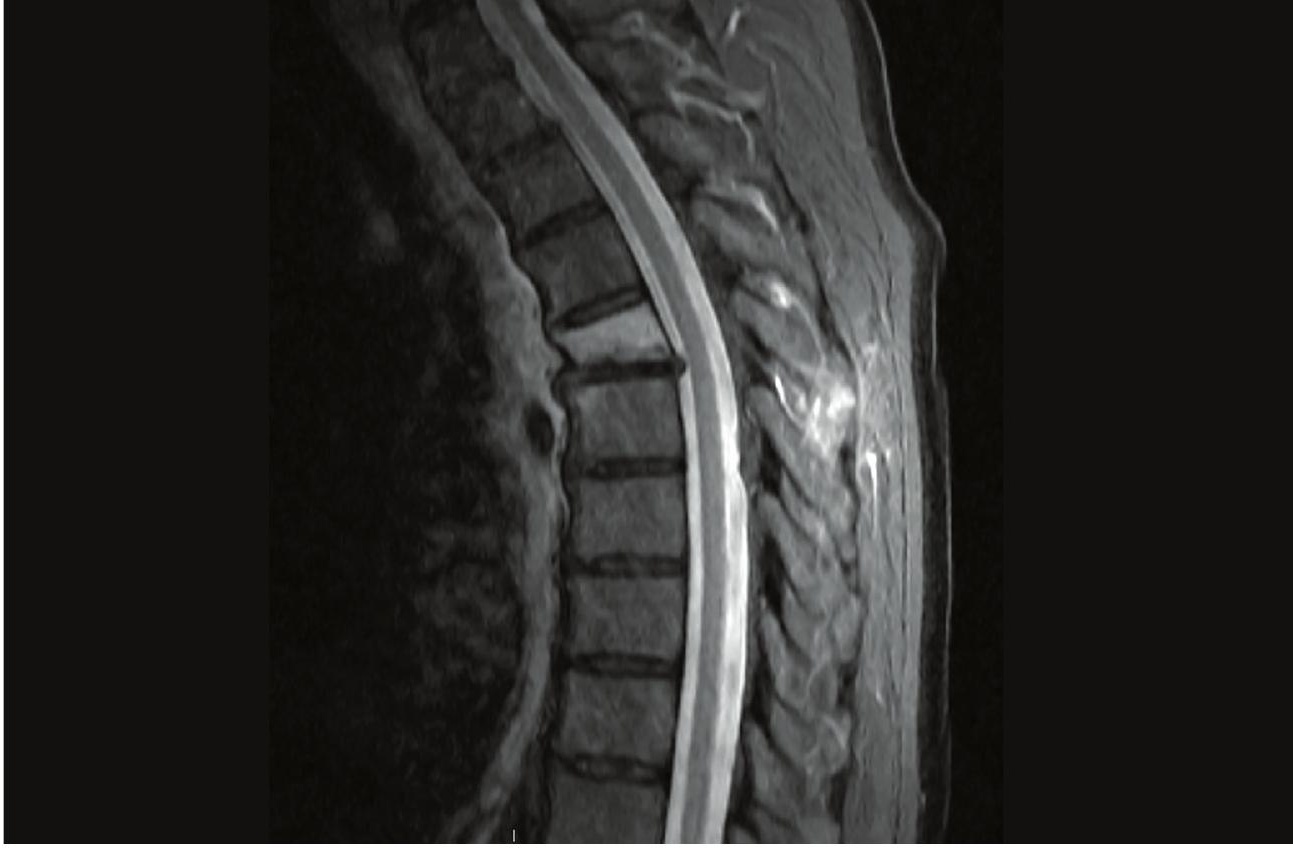

A stem-cell treatment for spinal-cord injuries will soon be available in Japan. JAPAN

\section{Stem-cell therapy raises concerns}

\section{Independent researchers warn that approval is premature.}

\section{BY DAVID CYRANOSKI}

J apan has approved a stem-cell treatment for spinal-cord injuries - the first such therapy for this kind of injury to receive government approval for sale to patients.

"This is an unprecedented revolution of science and medicine, which will open a new era of health care," says oncologist Masanori Fukushima, head of the Translational Research Informatics Center, a Japanese government organization in Kobe that has been giving advice and support to the project for more than a decade.

But ten specialists in stem-cell science or spinal-cord injuries, who were approached for comment by Nature and were not involved in the work or its commercialization, say the approval is premature, because there is insufficient evidence that the treatment works. Many of them say the approval for the therapy, which is injected intravenously, was based on a small, poorly designed clinical trial.

They say that the trial's flaws - including that it was not double-blinded - make it difficult to assess long-term efficacy, because it is hard to rule out whether patients might have recovered naturally. And, although the cells used - which are extracted from a patient's bone marrow and known as mesenchymal stem cells (MSCs) - are thought to be safe, the infusion of stem cells into the blood has been connected with dangerous blood clots in the lungs. And all medical procedures carry risks, which makes them hard to justify unless they are proven to offer a benefit.

"This approval is an unfortunate step away from everything researchers have learned over the past 70 years about how to conduct a valid clinical trial," says James Guest, a neurosurgeon at the Miami Project to Cure Paralysis at the University of Miami in Florida.

One inventor of the treatment, neurosurgeon Osamu Honmou of Sapporo Medical University in Japan, says he plans to publish a scientific paper that will discuss the clinicaltrial and safety issues. "I think it is very safe." He says he did not do a double-blinded study because Japan's regulations do not require it. "The most important point is that the efficacy is dramatic and definitive," adds Fukushima.

The unpublished results describe a trial of 13 people who had experienced spinal-cord injuries in the past 40 days. The team found that infusions of MSCs, which had been multiplied in the lab after they were extracted, helped the injured volunteers to regain some of the sensation and movement they had lost.

\section{EARLY GREEN LIGHT}

On the basis of these results, Japan's health ministry last month gave conditional approval for the treatment, called Stemirac. In the clinical trial, about 50 million to 200 million MSCs were intravenously infused back into patients 40 days after their injury to help repair the damage. The team can market and sell the therapy as long as they collect data from the participants over the next seven years that show that it works. People could start paying 